\title{
ANALISIS PENGENDALIAN MUTUCPO (Crude Palm Oil) MENGGUNAKAN SIX SIGMA DI PABRIK PENGOLAHAN CPOPT. GUNAJAYA KARYA GUMILANG KECAMATAN KENDAWANGAN KABUPATEN KETAPANG
}

\author{
IRIANTO SASTRO PRAWIRO ${ }^{1)}$, NOVIRA KUSRINI ${ }^{2)}$, NURLIZA $^{2)}$ \\ 1) Alumni Magister Manajemen Agribisnis Fakultas Pertanian Universitas \\ Tanjungpura Pontianak. \\ 2) Staf Pengajar Fakultas Pertanian Universitas Tanjungpura Pontianak \\ Email: rian_poli@yahoo.com, 082159548612
}

\begin{abstract}
The purpose of this research is to identify the quality of CPO in the palm oil Factory at PT Bumitama Gunajaya Agro. The analysis was carried out by processing the data of free faty acid, water level, and impurity level. Descriptive analysis was applied in this reaserch by using six sigma the use of six sigma aimed to identify if the quality which was produces by the company has relied on the standard wanted by the consumer.

The result reported that the quality of free faty acid remained at level of 1,3 sigma with DPMO value 317500 products that were underqualified as decided by SNI. The improvement that can be applied as in fish bone diagram was to the human resources, the propellents, and the machines. The analysis result at water quality sigma level has been at level 3 of sigma but with DPMO value by 2700hence, having analysed by Fish Bone Diagram, machinery was the factor that sould be improve in order to improve the sigma level. Meanwhile, impurity content has approximentely reached level 4 sigma, in this case reaching the company's target that expect the CPO quality above 3 level sigma. Therefore, at impurity content, it was unnecessary to find the problem about the quality inapporiateness with the consumer's standart (SNI).

Keywords: Six Sigma, CPO Quality, Free Faty Acid, Water Level, Impurity Level

\section{PENDAHULUAN}

Perkebunan kelapa sawit di Indonesia mempunyai peran yang sangat strategis dari sisi ekonomi antara lain sebagai komoditas ekspor, penyerapan kesempatan kerja, menekan jumlah penduduk miskin, mendorong pusat pertumbuhan wilayah, mencukupi kebutuhan konsumsi dalam negeri, dan lain-lain. Berdasarkan data tahun 2007, Indonesia telah menjadi Negara penghasil CPO terbesar di dunia dengan total produksi sekitar 16 juta ton. Sementara negara tetangga kita Malaysia yang selama ini berada pada posisi no.1, saat ini berada pada posisi ke-2 dengan total produksi sebesar 15,8 juta ton. Yang menarik dari data ini adalah ternyata Indonesia mampu menjadi negara penghasil CPO nomor 1 di dunia, 4 tahun lebih cepat dari prediksi sebelumnya, dimana Indonesia diperkirakan baru akan menjadi produsen CPO terbesar di dunia pada tahun 2010 (Berita Iptek: 2007).
\end{abstract}




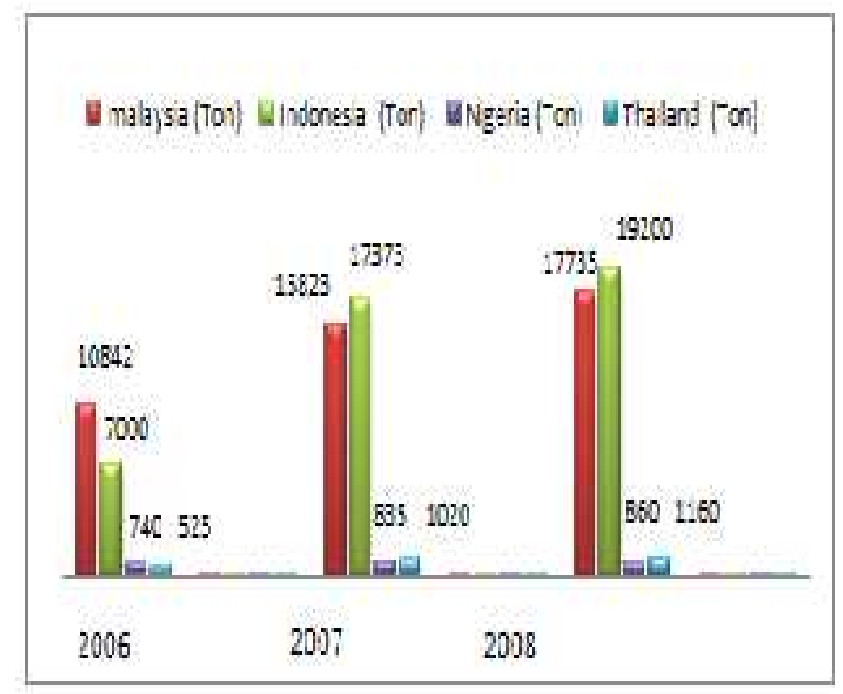

Gambar 1. Produksi Minyak Sawit DuniaSumber: MPOB (2009)

Kalimantan Barat termasuk ke dalam daerah yang memproduksi kelapa sawit. Perkebunan kelapa sawit itu sendiri telah dimulai di Kalimantan Barat. sejak tahun 1983 dan sampai saat ini Kalimantan Barat termasuk salah satu provinsi penghasil utama minyak kelapa sawit bagi Indonesia. Minyak kelapa sawit bagi Provinsi Kalimantan Barat merupakan salah satu komoditi yang cukup menunjang pembangunan. Perkembangan sector perkebunan kelapa sawit untuk daerah Kalimantan mengalami kemajuan yang cukup baik dari tahun 1999 luas areal 290.732 hektar dan produksi buah kelap sawitnya mencapai 301.868 ton/tahun mengalami peningkatan untuk tahun 2011 dengan luas areal perkebunan kelapa sawit 880.767 hektar dan produksinya 967.626 ton/tahun (Dinas Perkebunan Kalimantan Barat: 2011). Kabupaten Ketapang juga merupakan salah satu penghasil kelapa sawit terbesar didaerah Kalimantan memiliki luas areal perkebunan kelapa sawit yang masih belum menghasilkan $14.963 \mathrm{Ha}$ dan luas areal yang telah menghasilkan $81.436 \mathrm{Ha}$ dengan jumlah produksi sebesar 1.213.330 ton pertahun dengan Persentase luas areal perkebunan kelapa sawit ketapang di lingkup Kalimantan barat sebesar $11 \%$ (Badan Pusat Statistik Kabupaten Ketapang, 2009). PT. Bumitama Gunajaya Agro merupakan salah satu perusahaan Kelapa Sawit yang memiliki jumlah areal seluas 16.000 Ha dengan persentase $17 \%$ dari 70 perusahaan perkebunan yang berada dikabupaten Ketapang dengn areal yang luas. PT BGA memiliki permasalahan dalam hal mutu CPO yang masih belum sesuai dengan standar yang ditetapkan oleh SNI (Standar Nasional Indonesia) 


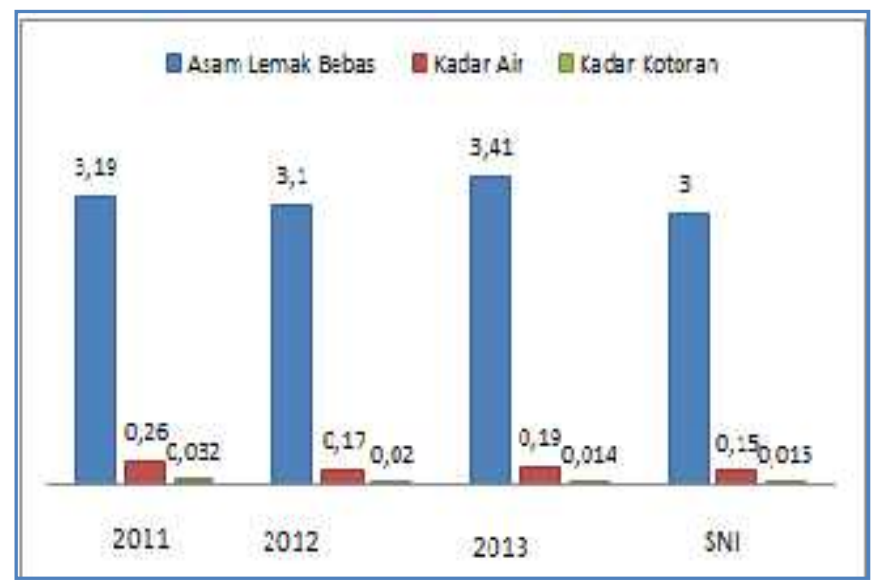

Gambar 2. Data Mutu CPO PT Bumitama Gunajaya Agro

(Sumber : Laporan Laboratorium PT. BGA, 2014)

Data mutu Cpo PT Bumitama Kendawangan pada periode 2011-2013 Menunjukan Asam lemak berfluktuatif berkisar antara $3-3,41 \%$, Kadar air cenderung menurun ; kadar kotoran cenderung menurun namun besaran tersebut rat-rata masih diatas standar yang disyaratkan oleh SNI. Oleh sebab itu fokus penelitian akan menggunkan six sigma menganalisis dan mengelola mutu berdasarkan ketiga kriteria tersebut untuk mencapai standar yang diharapkan yang pada akhirnya menuju pengoelolaan mutu yang berkelanjutan sehiiingga dapat mencapai zero defect.

\section{Landasan Teori}

Six Sigma merupakan suatu metode atau teknik pengendalian dan peningkatan kualitas dramatik yang merupakan terobosan baru dalam bidang manajemen kualitas. (Gaspersz, 2001). Ukuran kegagalan dalam Six Sigma yang menunjukkan kegagalan per sejuta kesempatan. Target dari Six Sigma adalah 3,4 DPMO (defect per million opportunities), yang diartikan dalam satu juta kali proses produksi terdapat kegagalan atau pketidak sesuaian sebanyak 3,4 kali. Penelitian Habib (2013) terkait pengendalian mutu minyak kelapa sawit. Menujukan Dari hasil penelitian diperoleh bahwa kadar asam lemak bebas berada diluar standar yang disebabkan oleh faktor manusia (SDM) yang kurang teliti, faktor bahan baku yaitu buah yang dipanen tidak tepat waktunya. Sedangkan pada kadar air penyebab standar yang tidak sesuai adalah manusia dan metode kerja, pada manusia kelelahan akibat jam kerja yang terlalu lama sehingga menyebabkan konsentrasi menurun, metode kerja yaitu pada perebusan yang tidak sempurna menyebabkan kadar air yang terdapat pada minyak kelapa sawit terlalu tinggi

Sukardi (2011) dengan penelitian berjudul aplikasi six sigma pada pengujian kualitas produk kripik apel. Hasil penelitianya menyatakan bahwa kemampuan proses (kapabilitas proses) secara keseluruhan menunjukan angka sebesar 271.300 hal ini menjukan bahwa jika dilakukan produksi kripik apel sebanyak 1000.000 kemasan maka terdapat 271.300 kemasan kripik apel yang tidak sesuai standar atau remuk. Faktor penyebab tidak standarnya produk kripik apel tersebut adalah manusia, mesin dan metode. 
Putu suciptawati (2011) dalam penelitianya yang berjudul analisis mutu ketebalan roti sisir. Hasil penelitian menunjukan terdapat proses yang berda diluar batas kendali, kondisi tersebut disebabkan manusia, bahan baku, dan mesin.

Proses pelaksanaan six sigma dilakukan oleh beberapa pihak yaitu: executive leader adalah pimpinan puncak yang berkomitmen pada pelaksanaan six sigma; champions adalah orang - orang yang sangat menentukan keberhasilan ataupun kegagalan dari six sigma; master black belt adalah orang yang bertindak sebagai penasehat (mentor) dan pemandu; black belt adalah tulang punggung budaya dan pusat keberhasilan six sigma; green belt adalah orang-orang yang membantu black belt di wilayah fungsionalnya. Pelaksanaan six sigma memiliki beberapa tahapan yang dikenal dengan DMIAC yaitu tahap Define/gambarkan peluang, Measure/ ukur pencapaian, analyze/ teliti kesempatan, Improve/ tingkatan capaian, Control/ kendalikan kinerja (Gasperz, 2001)

\section{METODE PENELITIAN}

Metode penelitian yang digunakan adalah deskriptif dengan lokasi Penelitian di PT. Bumitama Gunajaya Agro, di Kecamatan Kendawangan Kabupaten Ketapang jangka waktu Pelaksanaan 3 (Tiga) bulan, yang dilaksanakan mulai tanggal Januari s/d Maret 2014, penentuan lokasi Penelitian Tesis dilakukan secara sengaja atas dasar pertimbangan bahwa industri pengolahan CPO PT Bumitama Gunajaya Agro Merupakan perusahaan yang sedang berkembang di Kabupaten Ketapang. Sumber data didapat dari black belt (Manager pabrik) berupa data primer terdiri dari standar operasional prosedur, layout pabrik, profil perusahaan, struktur organisasi. Green belt (Asisten Pabrik) juga memberikan data berupa hasil analisa mutu asam lemak bebas, hasil analisa kadar air, dan hasil analisa kadar kotoran.

Metode pengambilan sample yang digunakan adalah pengambilan sample acak sederhana (simple random sampling) yaitu sebuah sample yang diambil sedemikian rupa sehingga penelitian atau satuan elementer dari populasi mempunyai kesempatan sama untuk dipilih sebagai sample. Pengambilan sample untuk peta kontrol X-bar dan R, peta kontrol X dan MR sebanyak 5 kali dalam setiap pengambilan sebanyak 20 sampel pengujian, yaitu sampel diambil selama 20 hari dalam satu hari terdapat 5 sampel yang diambil sehingga terdapat 100 sampel yang dianalisa. (vincent Gasperz, 1998).

Langkah - langkah analisis dalam six sigma pada penelitian ini terdiri dari

1. Define adalah pengidentifikasian permasalahan disini masalah yang diidentifikasi adalah mutu yang tidak sesuai dengan keinginan pelanggan yaitu pada mutu asam lemak bebas, kadar air, dan kadar kotoran.

2. Measure adalah mengukur/menganalisis permasalahan dari data yang ada. Dalam tahapan measure digunakan bebrapa alat analisis seperti, peta kontrol $\mathrm{X}$ dan $\mathrm{R}$, menghitung kapabilitas proses, DPMO serta mencari level sigma dari mutu yang dihasilkan. Adapun beberapa analisis diatas dijelaskan sebagai berikut :

3. Analisis adalah Proses industri harus dipandang sebagai suatu penigkatan terus-menerus, yang dimulai dari sederet siklus sejak adanya ide-ide untuk 
menghasilkan suatu produk (barang dan/atau jasa), pengembangan produk, proses produksi, sampai kepada distribusi kepada pelanggan.

4. Improve Memberikan perbaikan-perbaikan pada proses yang menghasilkan mutu tidak sesuai berdasarkan hasil analisa terdahulu

5. Control adalh Membuat rencana untuk mempertahankan hasil yang sudah bagus dari perbaikan agar dapat bertahan secara berkesinambungan.

\section{HASIL DAN PEMBAHASAN}

Berikut ini ditampilkan hasil analisis mutu CPO (Crude Palm Oil) beserta tahapan proses six sigma dalam bentuk tabe 1 .

Tabel 1. Tabel hasil analisis six sigma ada mutu CPO

\begin{tabular}{|c|c|c|c|c|}
\hline Define & Measure & Analyse & Improve & Control \\
\hline $\begin{array}{l}\text { Mutu atam lemvk } \\
\text { bebas tidik seruai } \\
\text { stander }(3,41 \%)\end{array}$ & $\begin{array}{l}\text { Hasil identifikasi } \\
C_{p}=0,33 \\
\text { DPMOO = } \\
\text { 317sooproses } \\
\text { Sigma }=1,3\end{array}$ & 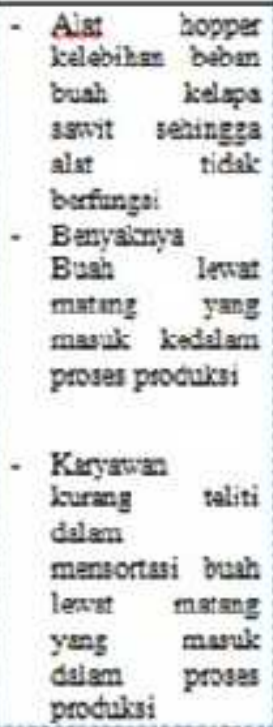 & 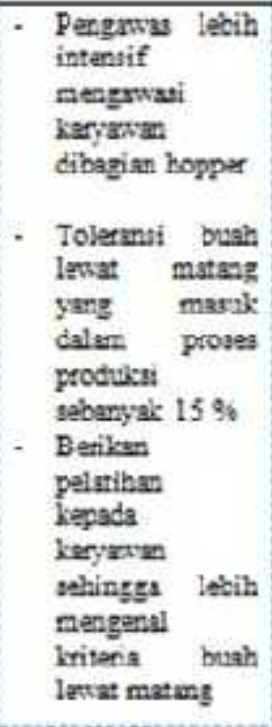 & 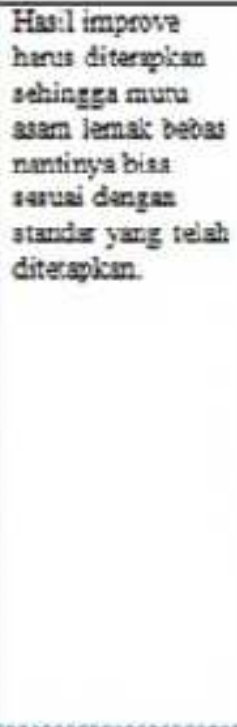 \\
\hline $\begin{array}{l}\text { Mutu badar air tidal } \\
\text { sesuai utandar } \\
(0,19 \%)\end{array}$ & $\begin{array}{l}\text { Huil identifiken: } \\
C P=0,39 \\
\text { DPMO }=2700 \\
\text { prosas } \\
\text { Signa=3 }\end{array}$ & $\begin{array}{l}\text { Kavaluanam alat } \\
\text { vacum drye } \\
\text { tidal: berada } \\
\text { pada nilai } 0,8 \ldots \\
1 \mathrm{~kg} / \mathrm{cm} 2\end{array}$ & $\begin{array}{l}\text { Jadwal } \\
\text { peawatus atat } 1 \\
\text { nizgou selidi }\end{array}$ & 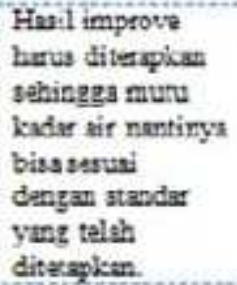 \\
\hline $\begin{array}{l}\text { Mutu kadar kototas } \\
\text { tidak sercei atendar }\end{array}$ & 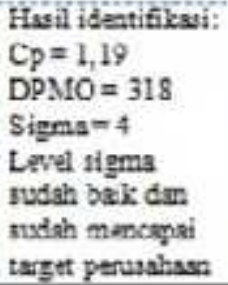 & $\because$ & $=$ & $\begin{array}{l}\text { Hencs tetsy } \\
\text { dilairvian } \\
\text { waliassi poda } \\
\text { muns rader } \\
\text { kotorta }\end{array}$ \\
\hline
\end{tabular}

Tahapan awal dalam proses pengendalian mutu CPO adalah define yaitu mendeteksi apakah terdapat mutu yang tidak sesuai dengan standar yang sudah ditetapkan (SNI). Data hasil analisis selama tahun 2014 mutu terdapat 3 mutu yang diidentifikasi tidak sesuai dengan standar SNI yaitu mutu asam lemak bebas dengan nilai 3,41 \% dan mutu kadar Air dengan nilai 0,19\%. Berdasarkan hasil identifikasi mutu CPO, asam lemak bebas dan kadar air masih diluar standar kualitas yang dikehendaki sehingga perlu dilakukan tahap selanjutnya untuk mengetahui penyebab terjadinya masalah, sedangkan untuk kadar kotoran sudah 
memenuhi standar kualitas tetapi dengan tahapan ini kita akan melihat apakah Kapabilitas proses dari mutu kadar kotoran sudah sangat baik atau masih perlu perbaikan.

Hasil Peta X didapat batas tengah (CL) dengan nilai 3, 2474, batas atas (UCL) dengan nilai 3,833, dan batas bawah (LCL) 2,6617, data sebaran mutu selama 20 hari tidak ada yang melewati batas kendali, tetapi pada sampel pda hari $5(2,894)$, $6(2,802)$ dan $7(2,894)$ sudah mendekati batas bawah. Peta kontrol R nilai batas tengah (CL) adalah 1,015, nilai batas atas (UCL) adalah 2,1457, dan nilai batas bawah (LCL) adalah 0 peta kontrol $\mathrm{R}$ memiliki fungsi sebagai memantau perubahan dalam hal penyebaranya, Memantau tingkat keakurasian/ketepatan proses yang diukur dengan mencari range dari sampel yang diambil.

Nilai kapabilitas proses pada asama lemak bebas sebesar 0,38 dengan artian kapabilitas proses masih rendah sehingga perlu dilakukan perbaikan, Sedangkan untuk Pengukuran DPMO atau banyaknya ketidak sesuaian produk yang dihasilkan dalam satu juta produk yang diproduksi adalah 317500, dengan level sigma 1,3, masih belum sesuai dengan keinginan perusahaan yaitu berada pada level 3 sigma.

Bahan baku menjadi penyebab masalah pada mutu asam lemak bebas berdasarkan hasil wawancara dengan green belt sesuai dengan hasil penelitian Fajar, dalam jurnal yang berjudul Analisis Pengendalian Mutu (Quality Control) CPO pada PT Buana Wira Subur Sakti Dikabupaten Paser (2014) dikatakan bahwa " bahan baku pada PT Buana Wirasubur Sakti menjadi Penyebab masalah dikarenakan bahan baku sebagian masih berasal dari kebun masyarakat". pada proses pengolahan terdapat tandan buah segar yang lewat matang hal ini terjadi dikarenakan masuknya buah dari kebun masyarakat yang melebihi ketentuan perusahaan yaitu 15\%. Perbaikan yang dapat diberikan untuk bahan baku adalah buah lewat matang yang boleh masuk dalam proses tidak boleh melebihi 15\%. Mesin merupakan faktor penting dalam proses pengolahan kelapa sawit, penanganan yang tepat dan perawatan yang baik sangat menentukan mutu produk yang akan dihasilkan. sesuai dengan hasil penelitian Bukhari, dalam jurnal yang berjudul Aplikasi Statistical Quality Control dalam Pengendalian Mutu Minyak Kelapa Sawit Di PKL Pagar Merbau PTPN. II Sumatera Utara (2012) dikatakan "faktor penyebab asam lemak bebas diluar batas kendali adalah mesin perawatan mesin jarang dilakukan dan penanganan terhadap kerusakan mesin juga sering terlambat". Karena peranannya yang sangat penting maka perawatan mesin sangat perlu dilakukan sehingga proses produksi dapat berjalan dengan baik dan menghasilkan mutu sesuai harapan. Sumber daya manusia (karyawan) memiliki peranan penting dalam menghasilkan CPO yang memiliki mutu baik, proses pengolahan CPO sering kali terhambat dikarenakan kurang telitinya para karyawan, sesuai dengan hasil penelitian Bukhari, dalam jurnal yang berjudul Aplikasi Statistical Quality Control dalam Pengendalian Mutu Minyak Kelapa Sawit Di PKL Pagar Merbau PTPN. II Sumatera Utara (2012) dikatakan "faktor penyebab asam lemak bebas diluar batas kendali adalah manusia, ketelitian dan keahlian menjadi faktor kunci dalam pelaksanaan operasional PKS Pagar Merbau" .

Mutu kadar air masih berda diluar batas kendali berdasarkan hasil peta control X didapat batas tengah (CL) dengan nilai 0,1945, batas atas (UCL) dengan nilai 0,2184, dan batas bawah (LCL) 0,1705, data sebaran mutu selama 20 hari tidak ada yang melewati batas kendali. Tetapi untuk sampel pada hari ke $16(2,18)$ dan 
$17(2,18)$ sampel mutu kadar air hampir mendekati batas atas. kondisi ini belum menjadi masalah dikarenakan masih berada dalam peta Kontrol Tetapi kondisi tersebut harus menjadi perhatian perusahaan untuk mencari penyebab mengapa ketiga sampel tersebut bisa mendekati batas kontrol atas. Peta kontrol $\mathrm{R}$ nilai batas tengah (CL) adalah 0,0415 , nilai batas atas (UCL) adalah 0,0877 , dan nilai batas bawah (LCL) adalah 0 peta kontrol $\mathrm{R}$ memiliki fungsi sebagai memantau perubahan dalam hal penyebaranya, Memantau tingkat keakurasian/ketepatan proses yang diukur dengan mencari range dari sampel yang diambil. Nilai kapabilitas proses pada asam lemak bebas sebesar 0,93 dengan artian kapabilitas proses masih rendah sehingga perlu dilakukan perbaikan, sedangkan nilai DPMO adalah 2700 sedangkan level sigmanya adalah 3 sigma Pada tahap analisa dilakukan analisa penyebab masalah mutu kadar air menggunakan diagram sebab akibat berdasarkan hasil wawancara dengan pihak green belt Mesin merupakan faktor penting dalam proses pengolahan kelapa sawit, penanganan dan perawatan peralatan merupakan faktor penting yang harus dilakukan. Sesuai dengan hasil penelitian Bukhari, dalam jurnal yang berjudul Aplikasi Statistical Quality Control dalam Pengendalian Mutu Minyak Kelapa Sawit Di PKL Pagar Merbau PTPN. II Sumatera Utara (2012) dikatakan "faktor penyebab kadar air diluar batas kendali adalah mesin perawatan mesin jarang dilakukan dan penanganan terhadap kerusakan mesin juga sering terlambat". Sehingga jadwal perawatan mesin harus dilaksanakan setiap 1 minggu sekali.

\section{KESIMPULAN DAN SARAN}

Mutu asam lemak bebas dan kadar air masih berada diluar batas kendali kondisi ini disebabkan oleh faktor SDM, bahan baku dan mesin, ketiga faktor ini yang sangat mempengruhi mutu tersebut sehingga pengawasan perlu dilakukan pada ketiga bagian tersebut. Oleh sebab itu perusahaan dapat melakukan perbaiakan dengan cara: (i) Perbaikan mutu pada asam lemak bebas ditujukan pada Pengawas dibagian hopper agar lebih intensif dalam mengawasi buah yang jatuh pada alat hopper, tidak mengizinkan buah yang lewat matang masuk kedalam proses produksi melebihi $15 \%$, Berikan pelatihan kepada karyawan sehingga lebih mengenal kriteria buah lewat matang.

1. Perbaikan mutu pada kadar air adalah diwajibkan setiap minggu untuk melakukan perawatan alat vacum dryer

2. Penelitian ini diharapkan dapat menjadi bahan acuan bagi peneliti selanjutnya, analisis pengendalian kehilangan minyak pada setiap stasiun pengolahan CPO dapat dijadikan alternatif untuk penelitian selanjutnya.

\section{DAFTAR PUSTAKA}

Amri, Q, " kebutuhan minyak nabati dunia bergantung kepada cpo indonesia". 15juni 2014.http://www.sawitindonesia.com/kinerja/2020.

Bent Flyvbjerg, 2006, "Five Misunderstandings About Case Study Research." 7 juni 2014. http//. Wikipedia.com.

Buchari.L, Merawati. 2013."Aplikasi Statistical Quality Control Dalam Pengendalian Mutu Minyak Kelapa Sawit di PKS Pagar Merbau PTPN 2 Sumatera Utara”, Jurnal Agribisnis. Vol 2. No 1. 
Devani, Marwiji, 2014." Analisis Kehilangan Minyak Pada Crude Palm Oil (CPO) Dengan Menggunakan Metode Statistical Quality Control", Jurnal Ilmu Teknik Industri. Vol 13. No 1

Fajar, D. 2014." Analisis Pengendalian Mutu (Quality Control) CPO (Crude Palm Oil) Pada PT. Buana Wira Subur Sakti di Kabupaten Paser". Jurnal Ilmu Administrasi Bisnis. Vol 2. No 2.

Gasperz, Vincent. 1998. Statistical Prosess Control, Penerbit Gramedia Pustaka Utama Jakarta, jakarta.

Gasperz, Vincent . 2003. Metode Analisis Untuk Meningkatkan Kualitas, Penerbit Gramedia Pustaka Utama, Jakarta.

Hadiguna, R. 2009." Model Persediaan Minyak Sawit Kasar di Tangki Timbun Pelabuhan". Jurnal Teknik Industri, Vol 11. No 2.

Satsuna, S," Definisi-Mutu-Menurut-Para-Ahli”, 5 juni 2014. http://www.scribd.com

Munir S, 2008, "Metode Penelitian: Desain penelitian (Reserch Design)", Fakultas Ekonomi Universitas Marcu Buana, Jakarta.

Suciptawati, Wella D, 2011," Analisis Mutu Ketebalan Roti Sisir pada perusahaan XYZ”, Jurnal Matematika, Vol 2, No. 1

Damayanti. 2007, "Analisis factor-faktor Pendukung Proses Implementasi Six Sigma studi kasus: PT. General Elektrik Lighting Indonesia”, Institut Teknologi Bandung, Bandung

Robert K. Yin. “Case Study Research. Design and Methods”. 15 Juni 2014. $\mathrm{http} / /$.wikipedia.com,

Rudi Kencana. 2009” Anlisis Pengendalian Mutu pada pengolahan minyak sawit dengan metode statistical quality control (SQC) pada PTP Nusantara IV Adolina, Universiitas sumatra Utara", Medan , 2009

Siegfried Lamnek. 2005 Qualitative Sozialforschung. Lehrbuch. Vol 4, www.wikipedia.com, 15 Juni 2014

Sugiyono. 2003, "metode penelitian bisnis". Pusat Bahasa Depdiknas. Bandung.

Sukardi, Usman Effendi, Diyah Ayu Astuti, 2011, Aplikasi Six Sigma pada pengujian kualitas produk di UKM kripik apel tinjauan dari aspek proses, Jurnal Teknologi Pertanian Vol. 12 No. 1

Suprapto." Teknik Pemanenan Dan Penanganan Pasca Panen Kelapa Sawit". 25 Maret 2014. http//pustakadunia.com.

Suwandi." Defects-per-Million-Opportunities-DPMO” 12 januari 2015. http://sixsigmaindonesia.com.

Tunggal. M, Ari, S. 2008," Penerapan Six sigma untuk meningkatkan kualitas produk bimoli classic: PT. Salim Ivomas Pratama Bitung”, Jurnal Teknik Industri, Vol 3, No. 1 